\title{
Drift-Dependent Confinement Requirements for Reinforced Concrete Columns Under Cyclic Loading
}

\author{
by Ingo Brachmann, JoAnn Browning, and Adolfo Matamoros
}

\begin{abstract}
The influence of transverse reinforcement and axial load on the drift limit of rectangular columns was investigated using test results from 184 specimens subjected to cyclic loading. Columns within the set were selected to have shear span-to-depth ratios of at least equal to 2.5 so that truss action would be the primary mechanism of shear resistance and the deformation component related to shear would be small compared with that related to flexure. Expressions relating the limiting drift ratio to the axial load ratio and the amount of confining reinforcement were evaluated. Equations indicating the amount of confining reinforcement required to achieve a given limiting drift ratio for reinforced concrete columns in regions of moderate and high seismicity are proposed.
\end{abstract}

Keywords: columns; flexure; load; reinforced concrete.

\section{INTRODUCTION}

Strength- and stiffness-based design philosophies produce competing analysis techniques for reinforced concrete columns subjected to cyclical lateral loads. Previous research has focused on developing relationships between the shear strength and the structural and material properties of columns (Ang, Priestley, and Paulay 1989; Wong, Paulay, and Priestley 1993; Watanabe and Ichinose 1991; Priestley, Verma, and Xiao 1994). These relationships relate the lateral load capacity of columns with the maximum deformation imposed on them. The yield displacement $\Delta_{\text {yield }}$ and the displacement at ultimate $\Delta u l t$ observed during tests were used to determine a displacement ductility factor $\left(\Delta_{\text {ult }} / \Delta_{\text {yield }}\right)$, which was used as the primary parameter to determine the degradation of the shear strength that occurs under cyclic loading as the lateral drift increases. Researchers (Park, Tanaka, and Lee 1998) have shown that the minimum amount of transverse reinforcement needed to adequately confine the concrete in columns is a function of the axial load, compressive strength of concrete, and yield strength of the transverse reinforcement.

The toughness of a column under lateral loads can also be defined in terms of the maximum lateral drift it can sustain without a significant loss in load-carrying capacity. With the emergence of performance-based design, drift has become a focal design parameter for reinforced concrete frames. Performance can be evaluated by the relative damage expected in a frame during an earthquake, gaged in terms of the expected mean drift (general frame distortion), story drift (average distortion of columns at a story), or element rotation (specific distortion of a particular element). Pujol (1997) provided some insight for linking column performance to a specific local distortion criterion by defining the limiting drift ratio at which no significant loss of shear capacity occurs in terms of the average shear stresses, the amount of transverse reinforcement, and the shear span-to-depth ratio. This paper seeks to establish a direct relationship between the limiting drift ratio and the corresponding material and structural properties of reinforced concrete columns. The study focused on columns that were not shear-critical (failure modes were not in shear) and had intermediate shear span-to-depth ratios for which confinement, not shear strength, was the primary consideration for proportioning the amount of transverse reinforcement. The proposed relationships were based on the premise that for intermediate columns (with shear span-to-depth ratios of at least 2.5), the capacity to sustain inelastic deformations, expressed in terms of the drift ratio, is approximately proportional to the plastic rotation that the column can sustain, and that the plastic rotation is dependent on the amount of confining reinforcement, the axial stress, and the compressive strength of concrete (Matamoros and Sozen 2003). The main objectives were to provide the means to detail columns for a required limiting drift ratio or to estimate the limiting drift ratio of a column based on the amount of transverse reinforcement.

\section{RESEARCH SIGNIFICANCE}

The maximum drift that a column can sustain while maintaining its load-carrying capacity is a significant performance parameter that is directly related to its material and structural properties. Expressions to estimate the limiting drift ratio of existing columns in terms of the amount of transverse reinforcement, the axial load, and the compressive strength of the concrete are proposed. In addition, recommendations are made about the amount of confinement that should be provided as a function of the expected drift demand, providing the means to detail columns for different levels of seismicity.

\section{COLUMN TEST DATA}

The proposed equations were calibrated based on data from 184 rectangular column specimens. The columns were subjected to cyclic loading under various loading protocols, with a majority of the data (135 column specimens) being taken from the reinforced concrete column test database provided by the University of Washington (Eberhard 2002). The remaining 49 test data were collected from various sources (Aschheim and Moehle 1992; Wight and Sozen 1973; Azizinamini et al. 1994; Lynn et al. 1996; Mo and Wang 2000). Details of the column data, including specific dimensions, material properties, and calculated limiting drift ratios, may be found elsewhere (Brachmann 2002).

ACI Structural Journal, V. 101, No. 5, September-October 2004.

MS No. 03-157 received May 1, 2003, and reviewed under Institute publication policies. Copyright @ 2004, American Concrete Institute. All rights reserved, including the making of copies unless permission is obtained from the copyright proprietors. Pertinent discussion including author's closure, if any, will be published in the July-August 2005 ACI Structural Journal if the discussion is received by March 1, 2005. 
Ingo Brachmann received his prediploma from the University of Dortmund, Germany, in 1998 and his MSCE from the University of Kansas, Lawrence, Kans., in 2002. He is completing his studies at the University of Dortmund.

ACI member JoAnn Browning is an assistant professor at the University of Kansas. She is a member of ACI Committees 341, Earthquake-Resistant Concrete Bridges; 374, Performance-Based Seismic Design of Concrete Buildings; 408, Bond and Development of Reinforcement; and ACI Subcommittee 318-D. Flexure and Axial Loads: Beams, Slabs, and Columns. Her research interests include dynamic response of concrete buildings, drift capacity of concrete columns, and durability of concrete structures.

ACI member Adolfo Matamoros is an assistant professor at the University of Kansas. He is Secretary of ACI Committee 408, Bond and Development of Reinforcement, and is a member of ACI Committees 341, Earthquake-Resistant Concrete Bridges; 439, Steel Reinforcement; and Joint ACI-ASCE Committee 445, Shear and Torsion. His research interests include shear design, detailing of structural concrete, and earthquake engineering.

The limiting drift ratio of the columns was defined as the displacement corresponding to $80 \%$ of the maximum shear strength $V_{\max }$ (Ang, Priestley, and Paulay 1989; Wong, Paulay, and Priestley 1993; Priestley et al. 1994; Matamoros and Sozen 2003). Tests in which the drift imposed on the columns was insufficient to cause significant strength decay were not included in the analysis because there was not a reliable way to define the limiting drift ratio. Because the main goal was to develop drift-dependent confinement requirements, only columns with aspect ratios exceeding 2.5 were included in the analysis to ensure that the selected specimens exhibit predominantly flexural response, and that the shear span-to-depth ratio did not have a strong influence on the strength of the members. A correction on the column displacement and maximum lateral load of the column specimens due to $P$ - $\Delta$ effects was completed as described by Brachmann (2002).

\section{RESEARCH PARAMETERS AND LIMITATIONS OF STUDY}

The parameters considered in the study included concrete compressive strength $f_{c}^{\prime}$, transverse reinforcement ratio ( $\rho_{\text {area }}=$ ratio of cross-sectional area of reinforcement to effective concrete area $[b \cdot s$, where $b$ is the element width, and $s$ is the spacing of the transverse reinforcement], or $\rho_{v o l}$ $=$ volume of reinforcement to volume of confined concrete), the yield strength of the transverse reinforcement $f_{y h}$, and the axial load $P$. The width-to-depth ratios for the column data used in the study ranged from 0.5 to 2.0 , with 147 out of 184 of the columns having square dimensions. Longitudinal reinforcement ratios ranged from 0.5 to $6.0 \%$. Ranges of additional properties of the columns included in the database are listed in Table 1. A dimensionless confinement parameter,

\section{Table 1-Range of properties in selected column database}

\begin{tabular}{c|c|c|c}
\hline $\begin{array}{c}\text { Parameter } \\
(1)\end{array}$ & $\begin{array}{c}\text { Variable } \\
(2)\end{array}$ & $\begin{array}{c}\text { Minimum } \\
(3)\end{array}$ & $\begin{array}{c}\text { Maximum } \\
(4)\end{array}$ \\
\hline Concrete compressive strength, $\mathrm{MPa}$ & $f_{c}^{\prime}$ & 22 & 116 \\
\hline Volumetric transverse reinforcement ratio, $\%$ & $\rho_{\text {vol }}$ & 0.17 & 6.64 \\
\hline Area transverse reinforcement ratio, \% & $\rho_{\text {area }}$ & 0.07 & 3.05 \\
\hline Yield strength of hoop, $\mathrm{MPa}$ & $f_{y h}$ & 255 & 1262 \\
\hline Longitudinal reinforcement ratio, $\%$ & $\rho_{l o n g}$ & 0.5 & 6.0 \\
\hline Yield strength of longitudinal bars, $\mathrm{MPa}$ & $f_{y l}$ & 315 & 587 \\
\hline Aspect ratio & $a / d$ & 2.5 & 7.64 \\
\hline Axial load ratio, $\%$ & $P / A_{g} f_{c}^{\prime}$ & 0 & 70 \\
\hline
\end{tabular}

similar to that used in Eq. (21-2) and (21-4) of the ACI 318 Building Code (ACI Committee 318 2002) was adopted $\left(c_{p}\right.$ $\left.=\rho f_{y h} / f_{c}^{\prime}\right)$. The commentary of ACI 318 (ACI Committee 318 2002) states that the theoretical basis for the confinement requirements in Eq. (21-2) and (21-4) (in terms of the parameter $c_{p}$ ) was to provide sufficient transverse reinforcement to increase the strength of the confined core such that it would compensate for the reduction in cross-sectional area that occurs due to crushing of the concrete in the unconfined shell. Although this rationale is not directly related to the capacity to deform of a column under lateral loads, this form of confinement parameter was deemed reasonable because it has been demonstrated that transverse reinforcement has the effect of increasing the strain that concrete can sustain (Roy and Sozen 1964; Park, Priestley, and Gill 1982), and that confinement becomes less effective as compressive strength of concrete increases (Matamoros and Sozen 2003).

\section{DRIFT RATIO AT YIELD}

Because the drift at yield, defined as the lateral displacement at the onset of yielding of the longitudinal reinforcement, is difficult to calculate in a reliable manner for the columns in the data set (a discussion on this topic is presented by Konwinski [1996]), an approximate method based on the load-deformation curve for each column was used to determine yield displacement. The yield point of a column was defined as the intersection of the linearly increasing portion of the curve in the elastic displacement range and the horizontal line at maximum shear load $V_{\max }$. The slope of the linear portion in the elastic displacement range was defined as the ratio of $75 \% V_{\max }$ to its corresponding displacement value $\left(\Delta_{@ 75 \% V \max }\right)$. The drift ratio at yield was defined as the ratio of the yield displacement to the length of the structural member. This definition was adopted because it provided a better representation of the yield point in the load-displacement curve of members with high axial load ratios, for which there may be a significant reduction in stiffness prior to yielding of the longitudinal reinforcement.

Figure 1 shows the drift ratios at yield $D R_{\text {yield }}$ versus the volumetric confinement parameter $c_{p}$ for the selected experimental column data. Drift ratio was defined as the ratio of measured lateral drift to column length. The data plotted in Fig. 1 are based on the volumetric transverse reinforcement ratio, which is the ratio of the volume of

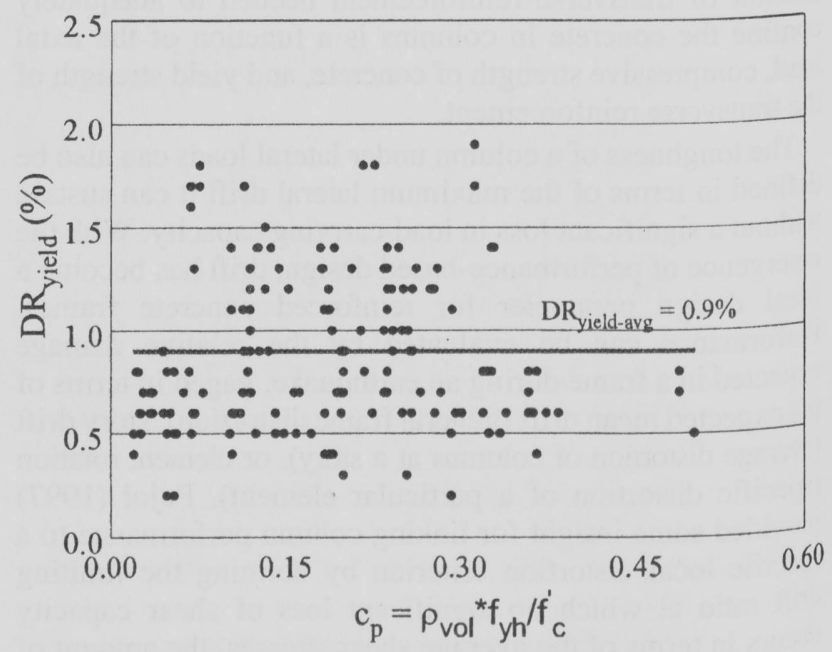

Fig. 1-Drift ratio at yield versus volumetric confinement parameter. 
confinement steel to the volume of concrete in the confined core. The data distribution and linear regression trend line show that the drift ratio at yield was approximately constant with respect to the volumetric confinement parameter and that, on average, yielding occurred at a drift ratio of approximately $1 \%$. This was to be expected because the amount of transverse reinforcement should have a negligible effect on the behavior of columns until the lateral expansion of concrete is large enough to generate significant stresses in the hoops, and this is likely to occur at drift ratios higher than that corresponding to yield.

Figure 2 shows the effect of the dimensionless axial load ratio (defined as the ratio of the axial load to the product of the concrete compressive strength and the gross crosssectional area) on the drift ratio at yield. The drift ratio at yield decreased with increasing axial load, contrary to what would be expected if the curvature at yield corresponded to the onset of yielding of the longitudinal reinforcement. Because an increase in axial load causes the neutral axis depth to increase, the curvature corresponding to yielding of the longitudinal reinforcement and, consequently, the yield displacement, should increase as the axial load increases. The observed trend can be attributed to the definition of the yield point that was adopted. Members with high axial load ratios exhibit significant reductions in stiffness prior to yielding of the reinforcement, an effect that becomes more pronounced as the axial load increases. The linear regression trend line shows that the average drift at yield for zero axial load was approximately $1 \%$ and decreased to $0.5 \%$ for an axial load ratio of $70 \%$, as reflected in Eq. (1)

$$
D R_{\text {yield }}(\%)=1-\frac{5}{7} \frac{P}{A_{g} f_{c}^{\prime}}
$$

\section{DUCTILITY RATIO}

The ductility ratio $\mu$ is commonly used to define the performance of reinforced concrete columns under cyclic loading. The relationship between ductility and limiting drift ratio as defined in this paper $\left(D R_{\text {lim }}\right)$ was explored to facilitate simple comparisons between expressions in terms of these two parameters.

A comparison of measured ductility ratios and corresponding limiting drift ratios is shown in Fig. 3, with a linear regression trend line of the data through the origin. Because the slope of the trend line was approximately equal to one, it is concluded that for the set of data considered, the ductility ratio was approximately equal to the limiting drift ratio

$$
\mu \cong D R_{\text {lim }} \quad\left(D R_{\text {lim }} \text { in \% }\right)
$$

The effects of axial load on the ductility and drift ratios are presented in Fig. 4. The ratios of ductility to limiting drift ratios are shown plotted with a trend line and ranges of one standard deviation above and below the trend line. The majority of the column data plotted within one standard deviation of the average. Using the average trend line shown, ductility can be expressed in terms of the limiting drift ratio and axial load ratio as shown in Eq. (3)

$$
\mu=\left(1+\frac{3}{2} \frac{P}{A_{g} f_{c}^{\prime}}\right) \cdot D R_{\text {lim }} \quad\left(D R_{\text {lim }}\right. \text { in \%) }
$$

Equation (3) shows that although ductility decreased with axial load, its rate of decrease was less than that of the drift limit.

\section{EFFECT OF CONFINEMENT AND AXIAL LOAD ON LIMITING DRIFT RATIO}

The primary objective of the study was to define a relationship between the limiting drift ratio (approximately proportional to the average rotation over the plastic hinge length) of reinforced concrete columns and their material and structural properties.

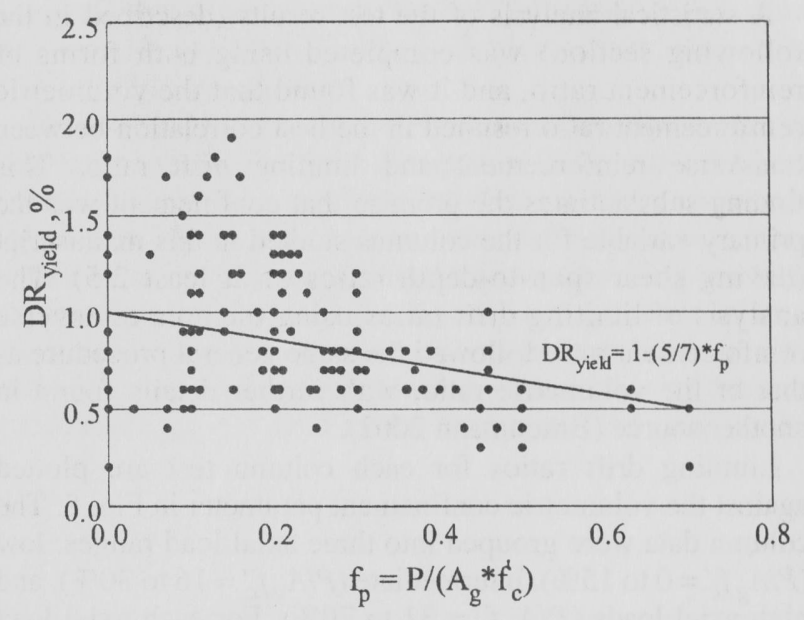

Fig. 2-Drift ratio at yield versus axial load ratio.

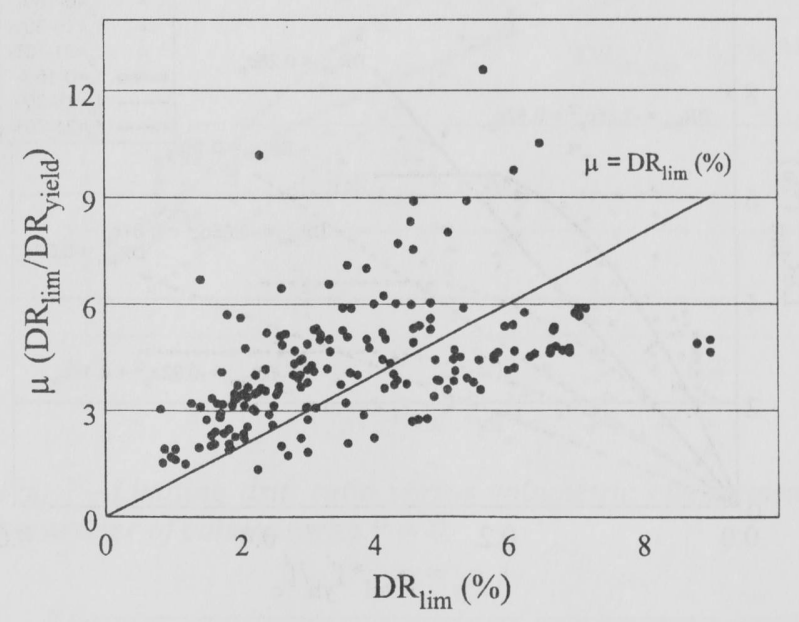

Fig. 3-Ductility ratio versus limiting drift ratio.

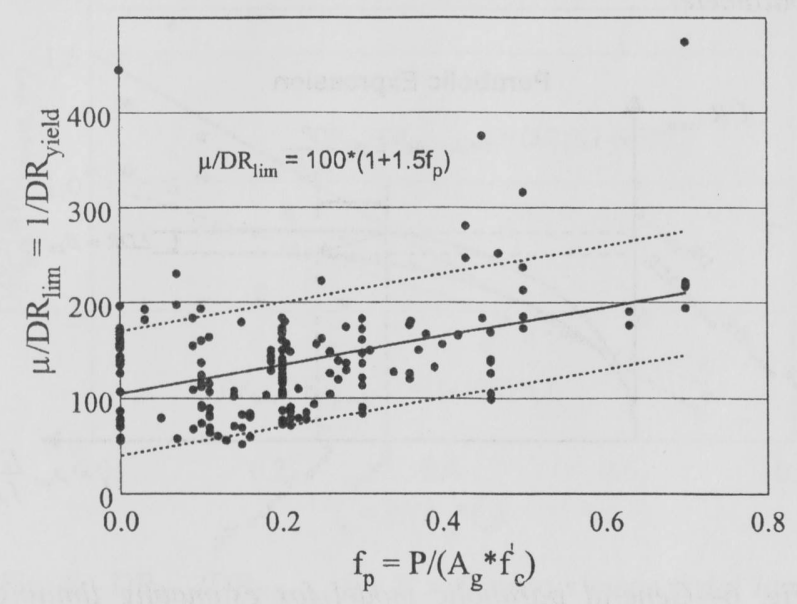

Fig. 4-Ductility/limiting drift ratio versus axial load ratio. 
The transverse reinforcement ratio in the confinement parameter $c_{p}$ can be expressed in terms of either a ratio of steel and concrete areas or volumes. The area transverse reinforcement ratio $\left(\rho_{\text {area }}\right.$ $=A_{v} / b s$, where $A_{v}$ is the area of shear reinforcement; $f_{y h}$ is the yield strength of the transverse reinforcement; $b$ is the width of the specimen; and $s$ is the spacing of the transverse reinforcement) is commonly used in expressions for shear design whereas the volumetric ratio $\rho_{y o l}$ is used primarily in expressions involving the amount of confining reinforcement (that is, Park, Priestley, and Gill 1982).

A statistical analysis of the test results (described in the following section) was completed using both forms of reinforcement ratio, and it was found that the volumetric reinforcement ratio resulted in the best correlation between transverse reinforcement and limiting drift ratio. This finding substantiates the premise that confinement was the primary variable for the columns studied in this manuscript (having shear span-to-depth ratios of at least 2.5). The analysis of limiting drift ratios using the area transverse reinforcement ratio followed the same general procedure as that of the volumetric ratio, with further details found in another source (Brachmann 2002).

Limiting drift ratios for each column test are plotted against the volumetric confinement parameter in Fig. 5. The column data were grouped into three axial load ranges: low $\left(P / A_{g} f_{c}^{\prime}=0\right.$ to $\left.15 \%\right)$, intermediate $\left(P / A_{g} f_{c}^{\prime}=16\right.$ to $\left.30 \%\right)$, and high axial loads $\left(P / A_{g} f_{c}^{\prime}=31\right.$ to $\left.70 \%\right)$. For each axial load

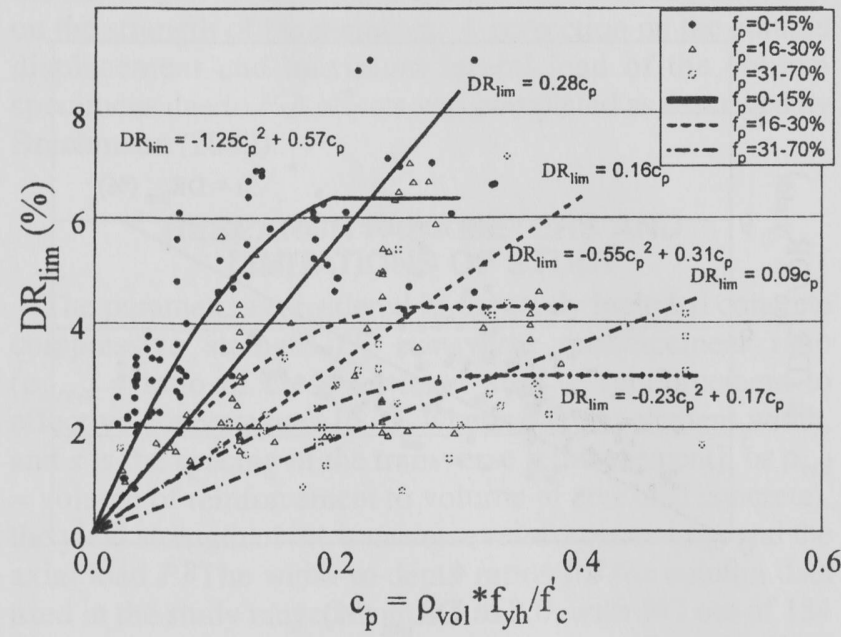

Fig. 5-Limiting drift ratio versus volumetric confinement parameter.

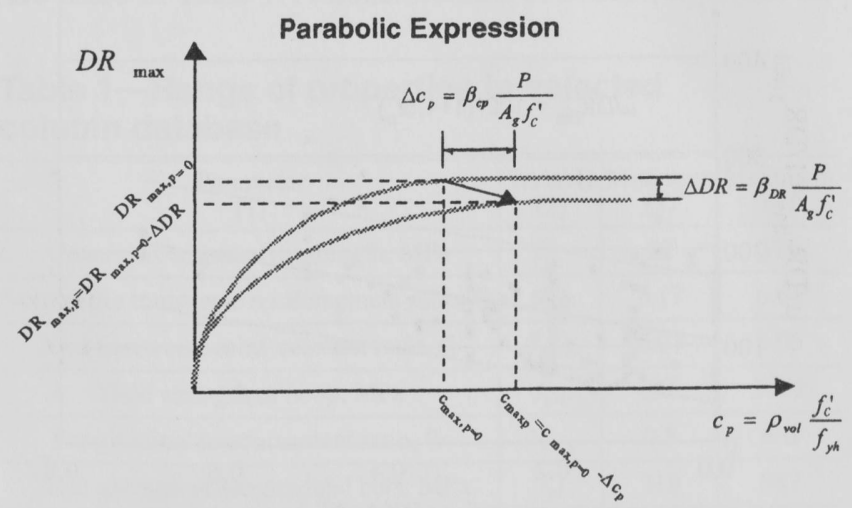

Fig. 6-General parabolic model for estimating limiting drift ratio. range, trend lines are presented corresponding to linear and parabolic functions. Several trends are noted from Fig. 5. Columns with low axial loads exhibited higher limiting drift ratios than columns with intermediate or high axial loads having similar confinement. The slopes of the trend lines show that the effect of increasing the amount of confinement was greater as the axial load decreased.

The effect of axial load was assessed by comparing the slope of the curve relating limiting drift ratios with the confinement parameter for various axial load ranges. Figure 6 shows that the limiting drift ratio had an approximately linear decreasing trend with respect to the axial load ratio. This linear reduction of the estimated limiting drift ratio $D R_{\text {lim, est }}$ with respect to the axial load was incorporated into the linear and square root relationships, resulting in two expressions with a similar format

Linear relationship

$$
D R_{\text {lim,est }}=\alpha c_{p}\left(1-\beta f_{p}\right)
$$

Square root relationship $\quad D R_{\text {lim, }, \text { st }}=\alpha \sqrt{c_{p}}\left(1-\beta f_{p}\right)$

where $c_{p}$ is the confinement parameter, $c_{p}=\rho_{v o l}\left(f_{c}^{\prime} / f_{y h}\right)$, and $f_{p}$ is the axial load ratio, $f_{p}=P / A_{g} f_{c}^{\prime}$. The constants $\alpha$ and $\beta$ are used to describe the influence of the confinement parameter and axial load ratio, respectively. Both of these relationships indicate that the limiting drift ratio increases with the amount of confinement. In the square root expression, the effect of additional transverse reinforcement on the limiting drift ratio decreases as the amount of transverse reinforcement increases, while in the linear expression, this effect remains constant.

Equation (4) and (5) can be transformed to provide an estimated transverse reinforcement ratio $\rho_{\text {vol,est }}$ for a selected limiting drift ratio $D R_{\text {lim }}$

$$
\rho_{\text {vol, est }}=\frac{1}{\alpha f_{y h}^{\prime}\left(1-\beta R_{p}\right)}
$$

$$
\text { Square root expression } \rho_{v o l, \text { est }}=\frac{f_{c}^{\prime}}{f_{y h}}\left(\frac{D R_{\text {lim }}}{\alpha\left(1-\beta f_{p}\right)}\right)^{2}
$$

A final expression plotted in Fig. 5 follows a parabolic relationship between the confinement parameter and the limiting drift ratio

Parabolic expression

$$
D R_{\text {lim }, e s t}=D R_{\max , p}\left(\frac{2 c_{p}}{c_{\max , p}}-\left(\frac{c_{p}}{c_{\max , p}}\right)^{2}\right)
$$

where $D R_{\max , p}$ is defined as the maximum limiting drift ratio the column can sustain under an axial load $P$, and $c_{\max , p}$ represents the corresponding volumetric confinement parameter at this peak value. Figure 6 shows a qualitative description of the effect of axial load on the main parameters of the parabolic expression. According to the shown relationships, the increment in limiting drift that can be gained by adding transverse reinforcement decreases with axial load, the amount of confinement in the column, and compressive strength of concrete. Unlike the square root expression, the parabolic relationship sets an upper bound on the limiting 
drift ratio $D R_{\max , p}$ that can be obtained by increasing the amount of confinement, so that past this point, any additional transverse reinforcement will not result in an increase of the limiting drift ratio.

The parabolic expression presented in Eq. (8) can be transformed to provide an estimate of the transverse reinforcement ratio $\rho_{\text {vol,est }}$ needed to obtain a selected drift limit $D R_{\text {lim }}$

$$
\rho_{v o l, e s t}=c_{\max , p}\left(\frac{f_{c}^{\prime}}{f_{y h}}\right)\left(1-\sqrt{1-\frac{D R_{l i m}}{D R_{\max , p}}}\right)
$$

The values of $D R_{\max , p}$ and $c_{\max , p}$ are expected to change with the axial load ratio. The largest limiting drifts occur in members without axial load $D R_{\max , p}=0$, and the value of $D R_{\max , p}$ decreases with increasing axial load. The opposite is true for the required amount of volumetric confinement, which increases with increasing axial load. Statistical analyses (Brachmann 2002) showed that the transition (shown by the arrow in Fig. 6) is approximately linear, and $D R_{\max , p}$ and $c_{\text {max, }}$ can be expressed as follows

$$
\begin{gathered}
D R_{\text {max }, p}=D R_{\text {max }, p=0}-\beta_{D R} \frac{P}{A_{g} f_{c}^{\prime}} \\
c_{\text {max }, p}=c_{\text {max }, p=0}+\beta_{c p} \frac{P}{A_{g} f_{c}^{\prime}}
\end{gathered}
$$

where $\beta_{D R}$ is the slope of the maximum limiting drift function, and $\beta_{c p}$ is the slope of the volumetric confinement parameter function at $D R_{\max , p}$.

\section{AXIAL LOAD AND CONFINEMENT COEFFICIENTS}

The coefficients in Eq. (4) and (5) were determined based on the relationship between limiting drift ratio and confinement for members without axial load (Fig. 7). For each expression, a regression analysis was carried out to establish a trend line that included the origin as an initial data point. This trend

\begin{tabular}{|c|c|c|c|c|}
\hline $\begin{array}{l}\text { Expression } \\
\text { (1) }\end{array}$ & $\begin{array}{c}\alpha \\
(2)\end{array}$ & $\begin{array}{c}\beta \\
(3)\end{array}$ & & \\
\hline Mean linear, $\rho_{v o l}$ & $3 / 7$ & $4 / 3$ & & \\
\hline Mean square root, $\rho_{v o l}$ & $1 / 8$ & $10 / 9$ & & \\
\hline Design square root, $\rho_{v o l}$ & $1 / 12$ & $10 / 9$ & & \\
\hline Mean linear, $\rho_{\text {area }}$ & 1 & $7 / 5$ & & \\
\hline Mean square root, $\rho_{\text {area }}$ & $1 / 5$ & $8 / 7$ & & \\
\hline $\begin{array}{l}\text { Expression } \\
\text { (1) }\end{array}$ & $\begin{array}{c}D R_{\max , p}=0 \\
\text { (2) }\end{array}$ & $\begin{array}{l}\beta_{D R} \\
(3)\end{array}$ & $C_{\text {max }, p=0}$ & $\begin{array}{l}\beta_{c p} \\
(5)\end{array}$ \\
\hline Mean parabolic, $\rho_{v o l}$ & $6 / 100$ & $7 / 100$ & $1 / 5$ & $2 / 7$ \\
\hline Design parabolic, $\rho_{v o l}$ & $4 / 100$ & $4.5 / 100$ & $1 / 5$ & $2 / 7$ \\
\hline Mean parabolic, $\rho_{\text {area }}$ & $6 / 100$ & $7 / 100$ & $1 / 7$ & $1 / 12$ \\
\hline $\begin{array}{l}\text { Expression } \\
\text { (1) }\end{array}$ & $\begin{array}{c}c_{\max , p}=0 \\
(2)\end{array}$ & $\begin{array}{l}\beta_{c p} \\
(3)\end{array}$ & $\begin{array}{c}\beta \\
(4)\end{array}$ & $\begin{array}{l}\gamma \\
(5)\end{array}$ \\
\hline Design square root, $D R_{\text {lim }}=1 \%$ & - & - & $10 / 9$ & $1 / 10$ \\
\hline Design parabolic, $D R_{\text {lim }}=1 \%$ & $1 / 7$ & $1 / 12$ & $9 / 8$ & $1 / 4$ \\
\hline Design square root, $D R_{\text {lim }}=2 \%$ & - & - & $10 / 9$ & $2 / 10$ \\
\hline Design parabolic, $D R_{\text {lim }}=2 \%$ & $1 / 7$ & $1 / 12$ & $9 / 8$ & $1 / 2$ \\
\hline
\end{tabular}

\section{Table $2-\alpha$ - and $\beta$-values for linear, square root, and parabolic expressions}

line provided the basis for determining the confining reinforcement factor $\alpha$. Ratios of measured to estimated limiting drift ratio in all members of the database were calculated based on the coefficients derived for members without axial load, and were subsequently categorized into 12 different axial load ranges. Mean values of the measured to estimated limiting drift ratio for each load range were calculated. These ratios were plotted versus their corresponding mean axial load ratios according to Eq. (4) and (5) (Fig. 8). In both models, the axial load reduction factor $\beta$ was approximately linear and the slope of the trend line was used to obtain its magnitude. Table 2 shows the final values of $\alpha$ and $\beta$ for Eq. (4) and (5).

The coefficients for Eq. (8) were established in a similar manner. Column data were grouped according to axial load ratio and a parabolic trend line for each axial load range was developed. Axial load ranges were defined so that there would be at least 10 data points per group, resulting in a total of nine different ranges. Table 3 presents the mean axial load ratio, the trend line equation, the maximum limiting drift ratio $D R_{\max }$, and the corresponding volumetric confinement parameter $c_{\max }$ for each of the nine axial load ranges. The

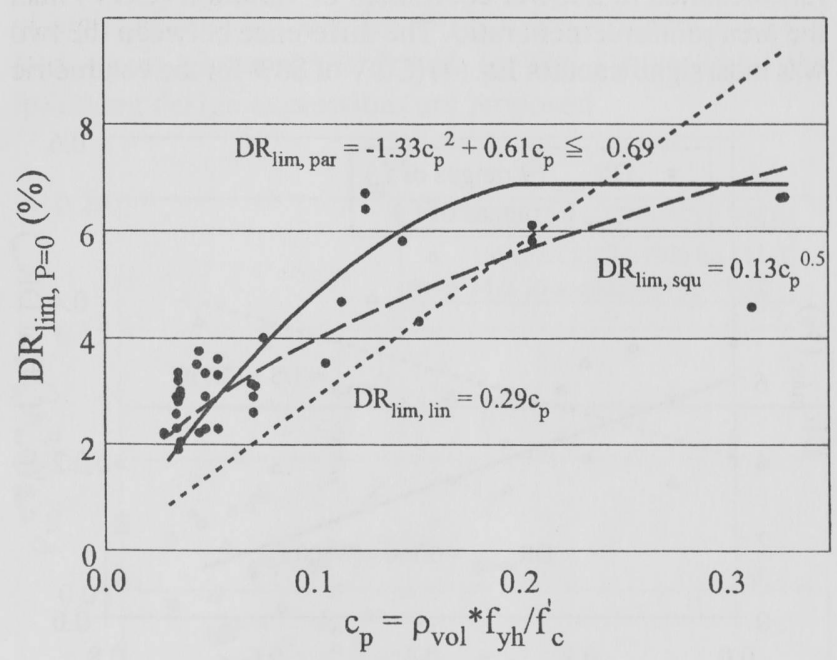

Fig. 7-Limiting drift ratio versus volumetric confinement parameter of columns with $\mathrm{P}=0$.

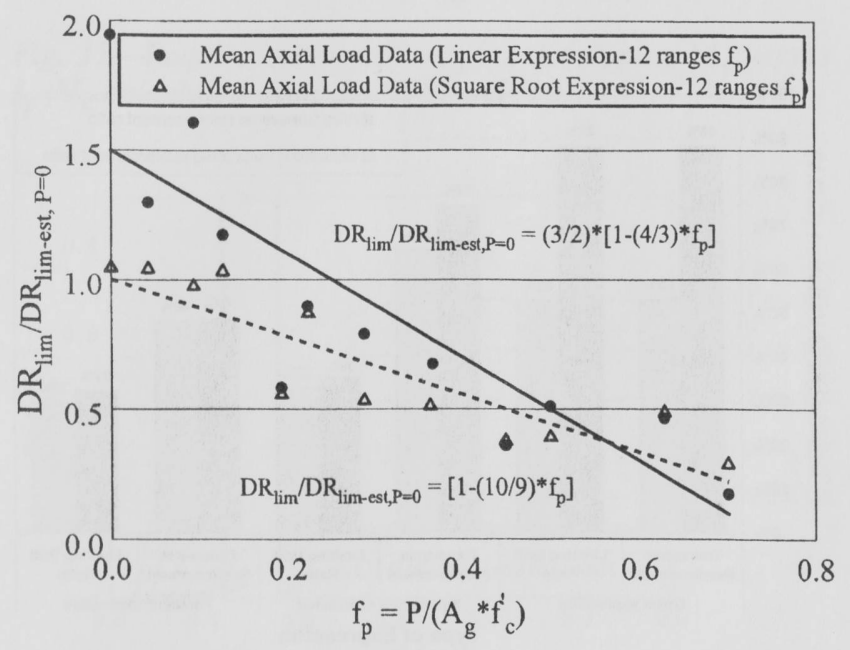

Fig. $8-\mathrm{DR}_{\mathrm{lim}} / \mathrm{DR}_{\text {lim-est }}$ for $\mathrm{P}=0$ versus mean axial load ratios. 
values of $D R_{\max }$ are plotted against their corresponding mean axial load ratios in Fig. 9 and are shown to decrease with increasing axial load. As previously mentioned, Eq. (9) was derived as a linear approximation of the maximum limiting drift ratios of each axial load range shown in Table 3.

The confinement values summarized in Table 3 indicate that the relationship between the volumetric confinement parameters at maximum limiting drift ratio $c_{\max , p}$ and the axial load ratio was also approximately linear (Fig. 9), following the form given in Eq. (11).

In essence, Eq. (10) and (11) indicate that the maximum drift attainable decreased as the axial load ratio increased, and that the amount of confining reinforcement needed to achieve a limiting drift ratio increased as the axial load ratio increased. Values for $D R_{\max , p=0}, c_{\max , p=0}, \beta_{D R}$, and $\beta_{c p}$ obtained from analyses using the volumetric and area transverse reinforcement ratios are presented in Table 2.

\section{RELIABILITY OF PROPOSED EXPRESSIONS}

Figure 10 shows the coefficients of variation for the ratio of measured to estimated limiting drift based on Eq. (4), (5), and (8). Generally, the use of the volumetric reinforcement ratio resulted in a lower coefficient of variation $(\mathrm{COV})$ than the area reinforcement ratio. The difference between the two was most significant for Eq. (4) (COV of $88 \%$ for the volumetric

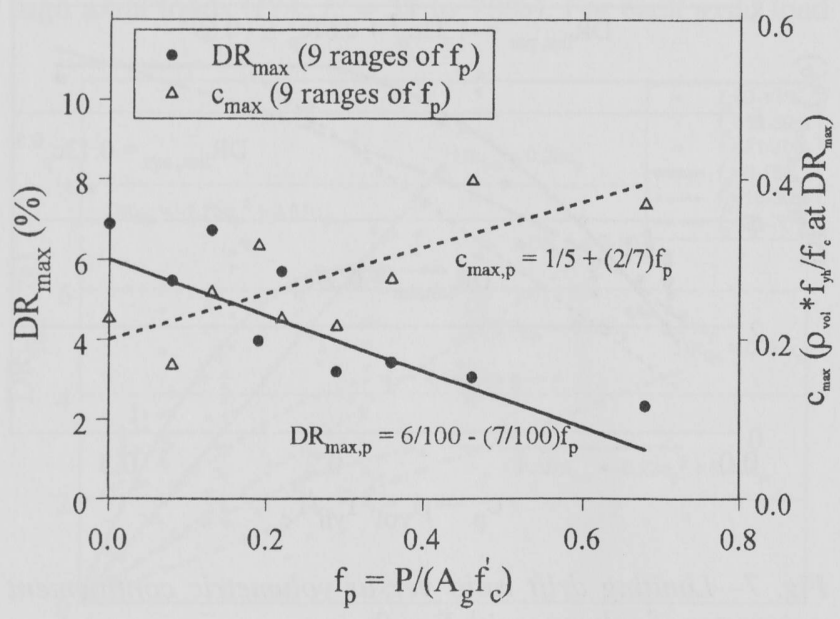

Fig. 9- $\mathrm{DR}_{\max }$ and $\mathrm{c}_{\max }$ versus mean axial load ratio.

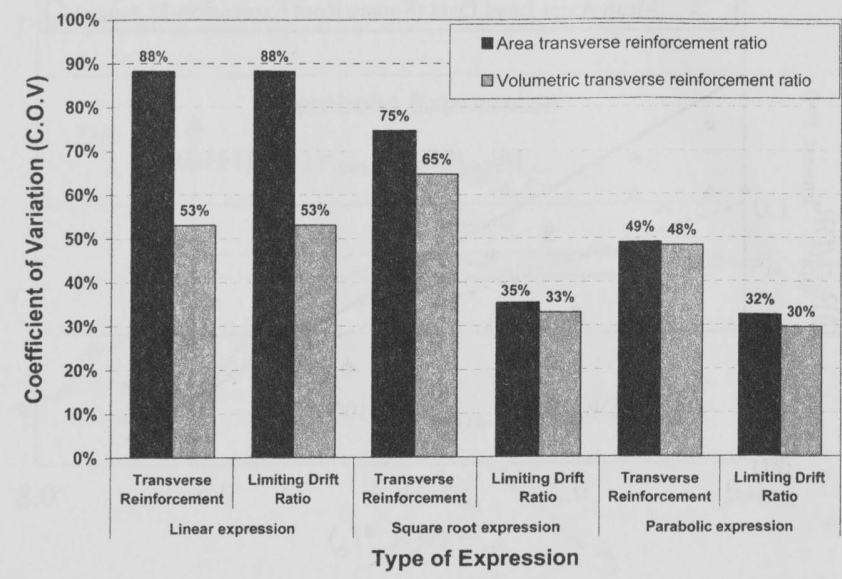

Fig. 10-COV for various estimation procedures and transverse reinforcement ratios. ratio compared with $53 \%$ for area ratio). Overall, the linear expression resulted in the highest COV for estimates of transverse reinforcement and limiting drift ratio, while the parabolic expression resulted in the lowest. This trend supports the conclusion that the effectiveness of confinement tended to decrease as the amount of confinement increased.

Although Eq. (8) does not include all parameters that can influence the limiting drift of columns, the parameters considered in the study resulted in accuracy that is comparable with that of other design expressions currently used in $\mathrm{ACI}$ 318 (ACI Committee 2002). For example, the COV for Eq. ( 8$)(\mathrm{COV}=0.3)$ is lower than that obtained by Reineck et al. (2003) when comparing the results of Eq. (11-2) of ACI 318 (ACI Committee 318 2002) to results from 361 static shear tests of slender beams $($ ald $>2.9, \mathrm{COV}=0.32)$.

Equation (5) and (8) were originally calibrated to provide an estimate of the mean limiting drift ratio. It was determined that approximately $60 \%$ of the estimates of limiting drift ratios and required volumetric reinforcement ratios were conservative if the coefficients obtained from the optimal curve fit were employed in Eq. (5) and (8). Because a higher confidence level of reaching the desired performance objective is needed for design, a safer estimate was sought by introducing a reduction factor for the limiting drift ratio and establishing a minimum requirement for the amount of transverse reinforcement. The coefficients were adjusted such that proposed equations would provide a safe estimate for the mean plus one standard deviation of the data. The design coefficients presented in Table 2 reflect this correction, reducing the probability of overestimating the limiting drift or underestimating the amount of reinforcement to approximately $16 \%$.

\section{MINIMUM AMOUNT OF CONFINEMENT}

A minimum amount of confinement is suggested to provide a threshold level of ductility. Equation (11-15) of ACI 318 (ACI Committee 318 2002) defines the shear strength provided by the transverse reinforcement based on a truss model with 45-degree struts as

$$
V_{s}=\frac{A_{v} f_{y h} d_{e f f}}{s}
$$

where $A_{v}$ is the area of the shear reinforcement. The volumetric reinforcement ratio can be expressed in terms of the area of the shear reinforcement, the width and height of the column core $\left(b_{c}\right.$

\section{Table 3-Maximum limiting drift ratios for axial load ranges}

\begin{tabular}{c|c|c|c|c}
\hline $\begin{array}{c}P / A_{g} f_{c}^{\prime} \text { range, } \% \\
(1)\end{array}$ & $\begin{array}{c}\text { Mean } P / A_{g} f_{c}^{\prime}, \% \\
(2)\end{array}$ & $\begin{array}{c}\text { Parabolic trend line } \\
(3)\end{array}$ & $\begin{array}{c}D R_{\max }, \% \\
(4)\end{array}$ & $\begin{array}{c}c_{\max } \\
(5)\end{array}$ \\
\hline 0 & 0 & $-1.33 c_{p}{ }^{2}+0.61 c_{p}$ & 6.88 & 0.23 \\
\hline 1 to 10 & 8 & $-1.92 c_{p}{ }^{2}+0.65 c_{p}$ & 5.46 & 0.17 \\
\hline 11 to 15 & 13 & $-1.00 c_{p}{ }^{2}+0.52 c_{p}$ & 6.72 & 0.26 \\
\hline 16 to 20 & 19 & $-0.39 c_{p}{ }^{2}+0.25 c_{p}$ & 3.96 & 0.32 \\
\hline 21 to 25 & 22 & $-1.11 c_{p}{ }^{2}+0.50 c_{p}$ & 5.69 & 0.23 \\
\hline 26 to 30 & 29 & $-0.68 c_{p}{ }^{2}+0.29 c_{p}$ & 3.18 & 0.22 \\
\hline 31 to 40 & 36 & $-0.45 c_{p}{ }^{2}+0.25 c_{p}$ & 3.42 & 0.28 \\
\hline 41 to 50 & 46 & $-0.19 c_{p}{ }^{2}+0.15 c_{p}$ & 3.04 & 0.40 \\
\hline 51 to 70 & 68 & $-0.17 c_{p}{ }^{2}+0.13 c_{p}$ & 2.32 & 0.37 \\
\hline
\end{tabular}


and $h_{c}$ ), and the spacing of the transverse reinforcement $s$. Substituting the relationship between volumetric reinforcement ratio and area of the transverse bar into Eq. (12), the shear strength $V_{s}$ can be expressed in terms of the volumetric reinforcement ratio $\rho_{v o l}$ as

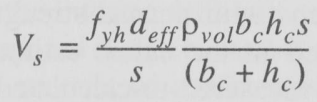

A symmetrical configuration of the transverse reinforcement (the same number of reinforcement legs in both directions) was assumed, which was consistent with over $95 \%$ of the column specimens in the data set. In addition, the dimension of the effective depth for the column was assumed to be approximately equal to the height of concrete core $\left(d_{\text {eff }} \approx h_{c}\right)$.

The minimum amount of confinement necessary to develop yielding of the column was determined based on the difference between the total shear demand and the shear strength provided by the concrete $V_{c}$

$$
\rho_{v o l} f_{\frac{y h}{f_{c}^{\prime}}}^{f_{c}}=\frac{\left(V_{y}-V_{c}\right)\left(b_{c}+h_{c}\right)}{b_{c} h_{c}^{2} f_{c}^{\prime}}
$$

Two expressions for $V_{c}$ (ACI 318 [ACI Committee 318 2002], Section 11.3.1) were used to determine amount of confinement needed to develop yielding of the columns

$$
\begin{gathered}
V_{c}=2\left(1+\frac{P}{2000 A_{g}}\right) \sqrt{f_{c}^{\prime}} b d_{e f f} \\
V_{c}=2 \sqrt{f_{c}^{\prime}} b d_{\text {eff }}
\end{gathered}
$$

Although these are lower bound expressions derived for static loading conditions, and it has been shown that the fraction of the total shear carried by the concrete changes as damage to the plastic hinge region increases (Wight and Sozen 1973; Matamoros and Sozen 2003), these expressions were deemed adequate for the purpose of developing a simple recommendation on the minimum amount of reinforcement needed to reach yielding of the columns and provide some level of ductility.

Figure 11 shows the amount of confinement required to reach yielding of the column specimens plotted with respect to the corresponding axial load ratio. The magnitude of the confinement parameter obtained with Eq. (15) for $V_{c}$ did not exceed a value of 0.10 , and for Eq. (16), a majority of the data were below 0.12 . As a result, a lower limit of 0.12 is recommended for the confinement parameter. Equation (21-2) and (21-4) of ACI 318 (ACI Committee 318 2002) currently recommend constant amounts of confinement (in terms of $\rho_{v o l}$ ) of 0.12 and 0.18 for spiral and square columns, respectively.

Estimates of required volumetric transverse reinforcement ratios in terms of a given limiting drift ratio must incorporate the minimum limit for the volumetric confinement described previously. When both the reduction factor and the lower limit for the confinement parameter were applied, the probability of exceeding the limiting value was reduced even further, and approximately $90 \%$ of the limiting drift and transverse reinforcement estimates were conservative.

\section{PROPOSED DESIGN EQUATIONS}

While Eq. (7) and (9) provided the best estimates of drift limits and volumetric transverse reinforcement ratios, Eq. (9) was more reliable. The required amount of confining reinforcement calculated using Eq. (9) for various levels of drift and axial load are shown in Fig. 12. The limiting drift ratios range from 1 to $3 \%$ and are plotted in $0.5 \%$ increments, for varying axial load ratios and volumetric confinement parameters. The vertical lines on the graph indicate the minimum required transverse reinforcement ratio as recommended by this study (broken line) and by ACI 318 (solid line).

The design graph shown in Fig. 12 is useful for estimating required amounts of confinement for reinforced concrete columns based on a prescribed performance objective in terms of the drift ratio. An interesting comparison can be drawn with the requirements of the ACI 318 (ACI Committee 318 2002) by conservatively assuming limiting drift ratios of 1.5 and $2.5 \%$ for regions of moderate and high seismicity, respectively. For moderate seismicity, the amount of confinement required by Eq. (9) is higher than the ACI requirement for axial load ratios above $45 \%$. In regions of high seismic demand, Eq. (9) is more stringent for axial load ratios above $25 \%$. Based on Eq. (9) to (11), the following design expressions are proposed

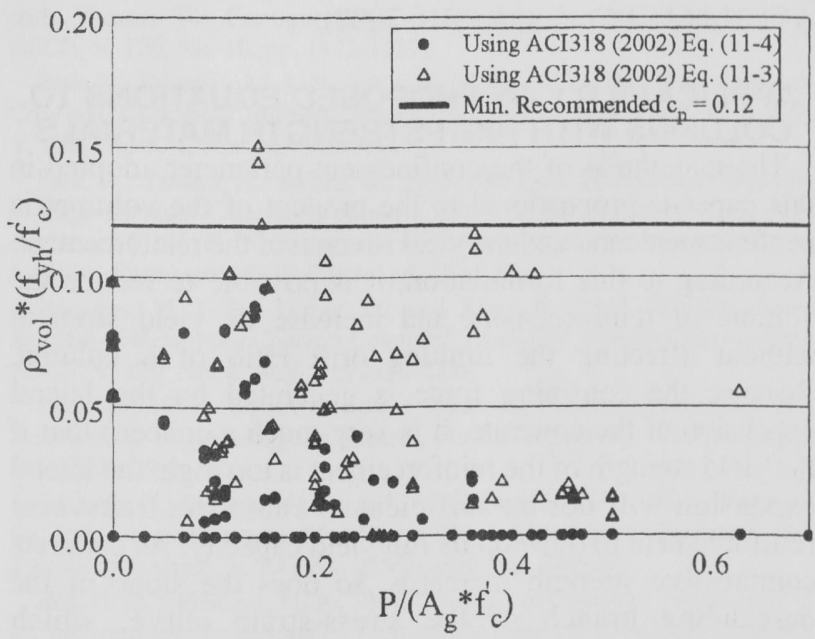

Fig. 11-Required volumetric $\mathrm{c}_{\mathrm{p}}$ for developing $\mathrm{M}_{\mathrm{y}}$ versus $\mathrm{f}_{\mathrm{p}}\left(\mathrm{V}_{\mathrm{c}}\right.$ calculated using Eq. (15) and (16)).

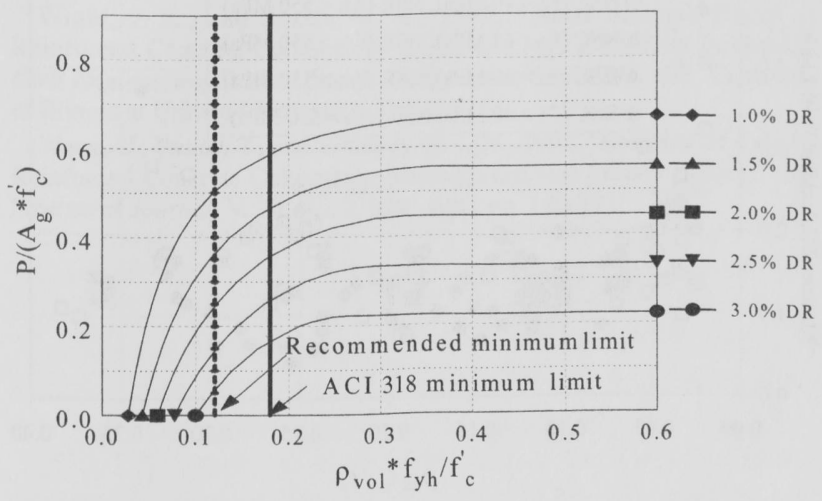

Fig. 12-Design graph for parabolic expression. 


$$
\rho_{\text {vol }}=c_{\text {max }, p}\left(\frac{f_{c}^{\prime}}{f_{y h}}\right)\left(1-\sqrt{1-\frac{D R_{\text {lim }}}{D R_{\max , p}}}\right) \geq 0.12 \frac{f_{c}^{\prime}}{f_{y h}}
$$

where

$$
\begin{gathered}
c_{\text {max }, p}=0.2+0.3 \frac{P}{A_{g} f_{c}^{\prime}} \\
D R_{\text {max }, p}=\frac{1}{100}\left(4-4.5 \frac{P}{A_{g} f_{c}^{\prime}}\right)
\end{gathered}
$$

In Eq. (17), $D R_{\text {lim }}$ is the limiting drift ratio, that is, 0.015 for moderate seismicity and 0.025 for high seismicity. As shown by Eq. (18) and (19), the values of $D R_{\max , p}$ and $c_{\max , p}$ in Eq. (17) are functions of the axial load ratio. The largest limiting drifts can be sustained by members without axial load $\left(D R_{\max , p=0}\right)$, and the value of $D R_{\max , p}$ decreases with increasing axial load. Conversely, the required amount of volumetric confinement to attain a drift ratio $D R_{\max , p}$ increases with increasing axial load.

Because the proposed equations are not intended to prevent premature bar buckling, and because data from rectangular columns is limited, their implementation must be made in conjunction with provisions for proper detailing of the transverse reinforcement, such as those in Section 21.4.4 of ACI 318 (ACI Committee 318 2002).

\section{APPLICABILITY OF PROPOSED EQUATIONS TO COLUMNS WITH HIGH-STRENGTH MATERIALS}

The magnitude of the confinement parameter adopted in this paper is proportional to the product of the volumetric reinforcement ratio and the yield strength of the reinforcement. According to this formulation, it is possible to reduce the volume of reinforcement and increase its yield strength without affecting the limiting drift ratio of a column. Because the confining force is generated by the lateral expansion of the concrete, it is very much a concern that if the yield strength of the reinforcement is too high, the lateral expansion will not be sufficient to cause the transverse reinforcement to develop its full yield capacity. As concrete compressive strength increases, so does the slope of the descending branch of the stress-strain curve, which implicates that this problem is likely to be more significant for high-strength concrete.

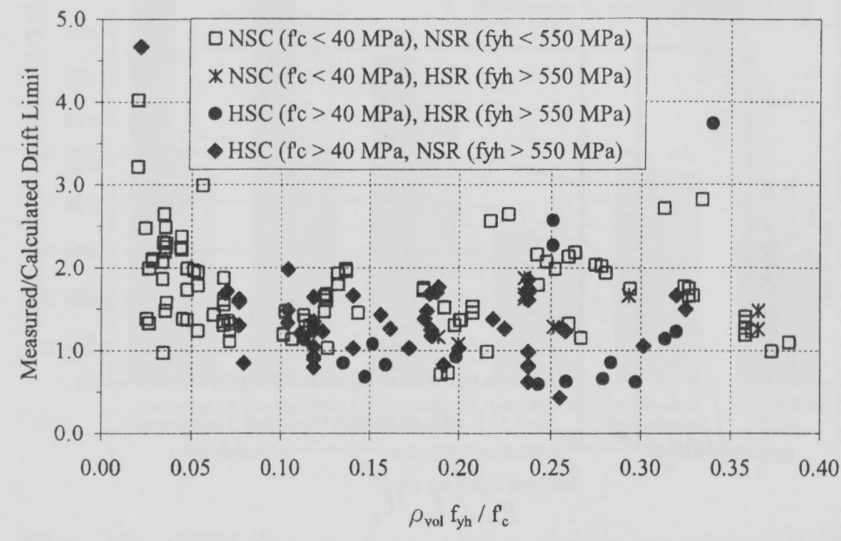

Fig. 13-Test/estimate ratios according to material strength.
To address this concern, column data were divided into four categories according to compressive strength of the concrete and yield strength of the transverse reinforcement. The thresholds were a concrete compressive strength of $40 \mathrm{MPa}(5.80 \mathrm{ksi})$ and a yield strength of $550 \mathrm{MPa}(80 \mathrm{ksi})$ (Fig. 13). The use of Eq. (8) with the design coefficients (Table 2) in specimens with normal-strength concrete and reinforcement resulted in the safest estimates of limiting drift, with an average measured-to-calculated ratio of 1.7 and a COV of 0.3. Specimens with high-strength concrete and normal-strength reinforcement and normal-strength concrete with high-strength reinforcement had comparable accuracy, with average ratios of measured-to-calculated limiting drift of 1.4 and 1.5, respectively. The proposed equations performed the worst for specimens with high-strength concrete and high-strength reinforcement. In this case, the average ratio of measured-to-calculated limiting drift was 1.2 with a COV of 0.7 . This is an indication that the lateral expansion of concrete in these specimens may not have been sufficient to cause yielding of the transverse reinforcement prior to failure. A significant improvement in this range was obtained by eliminating all specimens (a total of six columns) that had transverse reinforcement with yield strength of $1262 \mathrm{MPa}(180 \mathrm{ksi})$. These six columns had an average test-to-estimate ratio of 0.7 . If the yield strength of the reinforcement was limited to $830 \mathrm{MPa}(120 \mathrm{ksi})$, the average test-to-estimate ratio for specimens with high-strength reinforcement and high-strength concrete increased to 1.5 , which is comparable to that of the remaining data.

\section{SUMMARY AND CONCLUSIONS}

This study evaluated several relationships for reinforced concrete columns that relate the limiting drift ratio and the amount of confinement needed to sustain that limiting drift without significant loss in load-carrying capacity. These expressions may be used either to estimate the limiting drift ratio if the amount of confinement in a column is known or to select the amount of confining reinforcement needed to reach a drift limit. Regression analyses showed that for the data set considered, the limiting drift ratio was approximately equal to the ductility ratio, and that the ratio of these two quantities decreased with increasing axial load.

It was observed that the limiting drift ratio was primarily a function of the amount of transverse reinforcement, the yield strength of the hoops, the compressive strength of the concrete, and the axial load ratio. Among the three expressions developed to relate these parameters, a linear relationship provided the least reliable estimates of limiting drift, and the parabolic expression was the most accurate. Trends observed in the data indicate that the effect of confinement decreased as the amount of confinement, compressive strength of concrete, and the axial load ratio increased. Because the yield strength of the transverse reinforcement of the columns in the data set ranged between 255 and $1262 \mathrm{MPa}$ ( 37 and $183 \mathrm{ksi})$, the study showed that high-strength reinforcement may be used effectively to reduce the area of confining reinforcement required to reach a given drift limit, reducing congestion within plastic hinge regions. While the proposed equations provided safe estimates of the limiting drift of columns with compressive strengths up to $116 \mathrm{MPa}(16.8 \mathrm{ksi})$, it is recommended that these equations not be used when the yield strength of the reinforcement exceeds $830 \mathrm{MPa}$ $(120 \mathrm{ksi})$. The study also showed that the effect of confinement increased at a decreasing rate as the amount of 
